\title{
Nutritional risk screening 2002 and ASA score predict mortality after elective liver resection for malignancy
}

Thomas Zacharias, Nelio Ferreira

Department of Digestive, Hepatobiliary and Endocrine Surgery, Hôpital Emile Muller, Mulhouse, France

Submitted: 22 March 2015

Accepted: 10 May 2015

Arch Med Sci 2017; 13, 2: 361-369

DOI: https://doi.org/10.5114/aoms.2017.65273

Copyright $\odot 2017$ Termedia \& Banach

\section{Abstract}

Introduction: The aim of the study was to evaluate whether Nutritional risk screening 2002 (NRS 2002) at hospital admission may predict postoperative mortality and complications within 90 days after elective liver resection for malignancy.

Material and methods: A retrospective cohort study of a prospective database was performed. Two-hundred and three patients with elective liver resection for malignancy between 9 November 2007 and 27 May 2014 were included. Clinical data, NRS 2002, surgical procedures and histology were recorded. The primary endpoint was 90 -day mortality. Complications were registered within 90 days postoperatively according to the Clavien-Dindo classification.

Results: The 90 -day mortality was $5.9 \%$ and the overall complication rate was $59.1 \%$. Multivariate analysis identified NRS 2002 score $\geq 4$ (odds ratio $(\mathrm{OR})=9.24 ; p=0.005)$ and American Society of Anesthesiologists (ASA) score $\geq 3(\mathrm{OR}=6.20 ; p=0.009)$ as predictors of 90-day mortality. The 90day mortality was $27.6 \%(8 / 29)$ for patients with both risk factors (NRS 2002 score $\geq 4$ and ASA score $\geq 3)$ vs. $2.3 \%(4 / 174)$ for patients without or with only one risk factor $(p<0.001)$.

Conclusions: In the present study NRS 2002 score $\geq 4$ and ASA score $\geq 3$ were predictors of 90-day mortality after elective liver resection for malignancy.

Key words: liver resection, mortality, nutritional risk screening (NRS 2002).

\section{Introduction}

Indications for liver resection in malignancy have been extended in the last 20 years [1, 2]. Consequently, there has been an increase in the rate of elderly patients considered for liver resection [3-5] and a higher rate of liver parenchyma alterations caused by preoperative chemotherapy [6, 7], obesity [8] and viral hepatis [9]. Elderly patients with cancer and comorbidities have an increased nutritional risk $[10,11]$. There is good evidence that nutritional risk is associated with increased perioperative morbidity and mortality after gastrointestinal surgery [12-14].

Liver resection remains an intervention with considerable morbidity [1-8], and postoperative mortality in the $21^{\text {st }}$ century was reported as being "far from zero" [2] even in expert centers. Halliday et al. [15] reported in 1988 an increased mortality and complication rate after hepatobiliary surgery in patients with weight loss $>15 \%$ and albumin level $<30 \mathrm{~g} / \mathrm{dl}$.

\author{
Corresponding author: \\ Thomas Zacharias MD \\ Department of Digestive, \\ Hepatobiliary \\ and Endocrine Surgery \\ Hôpital Emile Muller \\ 20 rue du Dr Laennec \\ 68070 Mulhouse, France \\ Phone: +33 389647359 \\ Fax: +33 389647358 \\ E-mail: zachariast@ghrmsa.fr
}


More recently, low preoperative albumin [16] and prealbumin level [17] were confirmed as risk factors for complications [16] and liver insufficiency [17] after liver resection.

The European Society of Parenteral and Enteral Nutrition (ESPEN) recommends Nutritional risk screening 2002 (NRS 2002) for patients undergoing gastrointestinal surgery [18]. NRS 2002 is a reliable and reproducible tool for identifying patients at nutritional risk [19]. It has been studied prospectively in colorectal [14] and abdominal surgery [20] and was able to predict mortality and morbidity after surgery for colorectal cancer [14]. However, outcome data after liver resection are lacking.

Therefore, the aim of the present study was to evaluate the ability of NRS 2002 to predict mortality and complications within 90 days after elective liver resection for malignancy.

\section{Material and methods}

In the authors' institution 235 consecutive liver resections were performed between 9 November 2007 and 27 May 2014. Nine patients with emergency liver resection and 23 patients with benign disease were excluded. Therefore 203 elective liver resections for malignancy were included for analysis. Patients who required extrahepatic procedures such as simultaneous colorectal resection or others were included in the study.

The data were retrieved from a prospective liver resection database and retrospectively analysed. The following variables were recorded: age, gender, pathology, TNM stage, histology, preoperative nutritional support and chemotherapy, preoperative laboratory values (hemoglobin, albumin, bilirubin, prothrombin level), preoperative body weight, weight loss, body height, NRS 2002 score, comorbidities, American Society of Anesthesiologists (ASA) score, type of liver resection and associated procedures, length of operation and Pringle clamping time, estimated blood loss, perioperative transfusion, drainage, any postoperative complication and its treatment, postoperative nutritional support, mortality, length of hospital stay and latest news. Patients were followed up for at least 6 months. No patient was lost during follow-up.

All patients gave informed written consent for surgery and data collection. Ethics approval was not required because of the retrospective monocentric study design and local data analysis without data transmission [21].

\section{Preoperative management and nutritional risk screening}

Standard preoperative workup included blood analysis, computed tomography scanning or mag- netic resonance imaging in all patients. Indocyanine green clearance was performed in patients with liver cirrhosis and in patients undergoing major hepatectomy. Right portal vein embolization [22] or ligation was performed selectively before right (or extended right) hepatectomy if future liver remnant $(\mathrm{FLR})<30 \%$. Contraindications for liver resection were: liver cirrhosis Child-Pugh $B$ or $C$, insufficient $F L R$, technical impossibility to obtain complete resection of liver tumors and non-resectable extrahepatic disease. The preoperative NRS 2002 score was calculated for each patient according to Kondrup et al. [19]. The baseline level was given by an NRS 2002 score of 2, as all patients had 2 points attributed for the severity of disease. The maximal NRS 2002 score was 6 , corresponding to patients undergoing a liver resection ( 2 points) with severe impaired nutritional status ( +3 points) and age $\geq 70$ years (+1 point). Preoperative nutritional support was provided with oral immunonutrition (Oral-Impact for 7 days) as recommended by the French Society of Digestive Surgery, or occasionally with parenteral nutrition (Nutriflex for 7 days) when oral intake was insufficient [23].

\section{Surgical technique and peri-operative management}

After a bilateral subcostal incision, liver parenchyma transection was performed by the clamp crushing technique under intermittent portal triad clamping. Ultrasonography and a bile leakage test were performed routinely. Red blood cell transfusion was given when the hemoglobin level dropped below $8 \mathrm{~g} / \mathrm{dl}$ and according to hemodynamic tolerance. Antibiotics were given perioperatively according to guidelines [24].

\section{Postoperative management}

Postoperatively, patients were monitored in the intensive care unit (ICU) for at least $24 \mathrm{~h}$. An enhanced recovery protocol was not used during the study period. Patients started oral liquids intake the day after the operation and solid food was started at day 2 according to tolerance. Postoperative nutritional support was provided by the parenteral (Nutriflex) or enteral (Fresubin Standard) route in patients unable to eat solid food within 7 days, or with insufficient oral food intake [18, 23]. All patients had thromboprophylaxis with low molecular weight heparin.

\section{Definitions}

Major hepatectomy was defined as the resection of three or more liver segments. The Brisbane terminology was used for classification of the type of liver resection [25]. Extrahepatic procedures 
were defined as partial or total resection of other organs (colon, rectum, stomach, diaphragm, adrenal gland) and biliodigestive anastomosis. Cholecystectomy, liver biopsy and lymph node sampling or dissection were not considered as extrahepatic procedures.

Mortality was defined as death of any cause within 90 days after liver resection [26]. Overall complications were defined as any deviation from an uneventful postoperative course within 90 days after surgery. The diagnosis of an infectious complication was based on clinical, biological and radiological data and included: catheter, surgical site, pulmonary, and urinary infections. Infectious complications were defined according to the criteria established by the Centers for Disease Control and Prevention and the 1991 Consensus Conference [27], and were treated adequately with either antibiotics, percutaneous drainage or surgical revision. Wound infection was classified as surgical site infection. Severity of complications was defined according to the Clavien-Dindo classification [28]. Hospital stay was defined as postoperative hospital stay.

\section{Endpoints}

The primary endpoint was 90-day mortality. Secondary endpoints were infectious and overall complications within 90 days.

\section{Statistical analysis}

Continuous variables are given as median and range and compared using a Mann-Whitney test. Dichotomous variables are reported as $n(\%)$ and compared using a Pearson $\chi^{2}$ or Fisher's exact test, as appropriate. All statistical tests were two-sided and $p<0.050$ was considered significant. To assess which parameters may have influenced 90day mortality, uni- and multivariate analysis were performed. Stepwise logistic regression was used for multivariate analysis. All variables with $p<0.2$ in univariate analysis were included in the multivariate analysis. In multivariate analysis variables with $p \geq 0.1$ were excluded step by step.

\section{Results}

Baseline characteristics of the patient population and the indications for liver resection are shown in Table I. Nutritional risk (NRS $2002 \geq 3$ points) [19] was registered in $66.5 \%(135 / 203)$ of patients. The median value of the NRS 2002 score was 3 and was used for quantization in uni- and multivariate analysis. The type of liver resection, simultaneous extrahepatic procedures and intraoperative data are shown in Table II. Median hospital stay after the operation was 10 days (range: 4-90). Postoperatively, patients started oral liq- uids the day after the operation and solid food at median postoperative day 4 (range: $2-70$ ).

\section{Postoperative mortality}

There was no intraoperative death. Eight (3.9\%) patients died within 30 days as a result of the following: 4 septic shock (cholangitis, pneumonia, peritonitis caused by an anastomotic fistula after ileostomy closure, unknown origin), 2 liver failures, 1 stroke and 1 cardiac arrest. Four patients died within 90 days after surgery because of the following: tumor progression in two patients with a two-stage or reverse hepatectomy, pneumonia in 1 patient and septic shock caused by endo-

Table I. Baseline characteristics of 203 patients with elective liver resections for malignancy

\begin{tabular}{|c|c|}
\hline Parameter & Result \\
\hline Female gender & $55(27.1 \%)$ \\
\hline Mean age (range) [years] & $66.5(27-89)$ \\
\hline $\begin{array}{l}\text { Median Charlson Comorbidity Index } \\
\text { (range) }\end{array}$ & $6(2-12)$ \\
\hline \multicolumn{2}{|l|}{ NRS 2002 score: } \\
\hline 2 points & $68(33.4 \%)$ \\
\hline 3 points (= median) & $60(29.5 \%)$ \\
\hline 4 points & $31(15.2 \%)$ \\
\hline 5 points & $31(15.2 \%)$ \\
\hline 6 points & $13(6.4 \%)$ \\
\hline Median body weight (range) $[\mathrm{kg}]$ & $74(40-127)$ \\
\hline Median body height (range) [m] & $1.7(1.5-1.9)$ \\
\hline $\begin{array}{l}\text { Median weight loss in \% of usual } \\
\text { weight }\end{array}$ & $2.7(0-27)$ \\
\hline ASA Score $\geq 3$ & $69(33.9 \%)$ \\
\hline Albumin level < $35 \mathrm{~g} / \mathrm{l}$ & $24(11.8 \%)$ \\
\hline Preoperative chemotherapy & $68(33.4 \%)$ \\
\hline Preoperative nutritional support & $111(54.6 \%)$ \\
\hline Postoperative nutritional support & $72(35.4 \%)$ \\
\hline \multicolumn{2}{|l|}{ Pathology: } \\
\hline Colorectal cancer & $127(62.5 \%)$ \\
\hline Cholangiocarcinoma & $22(10.8 \%)$ \\
\hline Hepatocellular carcinoma & $42(20.6 \%)$ \\
\hline Other malignancy & $12(5.9 \%)$ \\
\hline Cirrhosis/fibrosis & $34(16.7 \%)$ \\
\hline
\end{tabular}

ASA - American Society of Anesthesiologists, NRS 2002 Nutritional risk screening 2002. Continuous variables are reported as median and range. Dichotomous variables are reported as $n$ (\%). Other malignancies included: liver sarcoma $(n=2)$, metastases of endocrine tumors $(n=2)$, other metastases $(n=8)$. 
Table II. Types of liver resection following the Brisbane terminology [25], extrahepatic procedures and intraoperative data for 203 patients with elective liver resections for malignancy

\begin{tabular}{|lc|}
\hline Type & Result \\
\hline Major hepatectomy: & $61(31.9 \%)$ \\
\hline Right hepatectomy & $33(18.8 \%)$ \\
\hline Left hepatectomy & $20(9.4 \%)$ \\
\hline Other & $8^{*}(3.1 \%)$ \\
\hline Minor hepatectomy: & $142(68.1 \%)$ \\
\hline \begin{tabular}{l} 
Extrahepatic procedures: \\
\hline Colorectal resection
\end{tabular} & $66(32.9 \%)$ \\
\hline \begin{tabular}{l} 
Biliodigestive anastomosis \\
\hline Other**
\end{tabular} & $60(18.3 \%)$ \\
\hline \begin{tabular}{l} 
Operating time [min] \\
\hline \begin{tabular}{l} 
Blood loss [ml] \\
\hline Pringle clamping:
\end{tabular}
\end{tabular} & $20(9.9 \%)$ \\
\hline $\begin{array}{l}\text { Clamping time [min] } \\
\text { Transfusion: }\end{array}$ & $168(82.7 \%)$ \\
\hline
\end{tabular}

Continuous variables are reported as median and range. Dichotomous variables are reported as $n$ (\%). *Three patients had two bisegmentectomies (4 resected segments) and 5 patients had trisegmentectomy classifying those resections as major hepatectomy. ${ }^{* *}$ Other extrahepatic procedures included: resection and anastomosis of the small intestine $(n=9)$, partial resection of the right diaphragm $(n=7)$, distal gastrectomy $(n=1)$, left pancreatectomy $(n=1)$ and right adrenalectomy $(n=2)$.

carditis with septic cerebral embolism in another patient. The overall 90-day mortality was 5.9\% $(12 / 203)$ and $4.4 \%(6 / 137)$ after liver resection only versus $9.1 \%(6 / 66)$ after liver resection with simultaneous extrahepatic procedures $(p=0.209)$. Six patients died within 90 days because of postoperative infectious complications, 5 presenting septic shock.

\section{Predictive factors for 90-day mortality}

Variables associated with 90-day mortality in univariate analysis were: ASA score $\geq 3$, NRS 2002 score $\geq 4$, albumin level $<35 \mathrm{~g} / \mathrm{l}$, major hepatectomy and transfusion, as shown in Table III. All factors with $p<0.2$ in univariate analysis were included in the multivariate analysis. In multivariate logistic regression analysis two independent risk factors were found for 90-day mortality: ASA score $\geq 3$ ( $p=0.009$; odds ratio $(\mathrm{OR})=6.20 ; 95 \%$ confidence interval $(\mathrm{Cl}): 1.56-24.53)$ and NRS 2002 score $\geq 4(p=0.005 ;$ OR $=9.24 ; 95 \% \mathrm{Cl}$ : 1.92-44.39) (Table IV). The numbers of patients alive and deceased within 90 days postoperatively according to the presence of these risk factors are shown in Figure 1. The 90-day mortality was $27.6 \%(8 / 29)$ for patients with both risk factors (NRS 2002 score $\geq 4$ and ASA score $\geq 3$ ) vs. 2.3\% (4/174) for patients without or with only one risk factor $(p<0.001)$.

\section{Subgroup analysis of 90-day mortality}

In all subgroups 90-day mortality increased for NRS 2002 score $\geq 4$. The effect was more pronounced in patients older than 70 years, in major hepatectomy and for extrahepatic procedures (Table V).

\section{Postoperative complications}

A total of 212 postoperative complications were registered in 120 (59.1\%) patients and were classified according to their severity in the Clavien-Dindo classification (Table $\mathrm{V}$ ). Procedures under general anaesthesia (Clavien-Dindo IIIb) were performed in 13 (6.4\%) patients: surgery in 8 patients because of the following: 1 bile leakage, 1 hemoperitoneum, 1 ischemic colonic perforation, 1 anastomotic leakage after ileostomy closure, 1 ileal perforation caused by adhesiolysis, 1 exploratory laparotomy, 1 endocarditis, 1 pleural empyema; endoscopic procedures in 4 patients ( 3 biliary stents and 1 hemostatic clip) and interventional radiology in 1 patient (portosystemic shunt). No anastomotic leakage after simultaneous colorectal resection was recorded. Procedures under local anesthesia (Clavien-Dindo IIla) were performed in 20 (9.8\%) patients: percutaneous drainage of abdominal collections in 8 (3.9\%) patients, percutaneous drainage of pleural collections in $10(4.9 \%)$ patients, 1 coronarography and 1 pyelostomy.

Nutritional risk measured with the NRS 2002 score was not associated with a higher overall and infectious complication rate. On the other hand, more patients with NRS 2002 score $\geq 4$ had septic shock (Table V). Patients with postoperative septic shock had a mortality rate of $41.6 \%(5 / 12)$.

\section{Discussion}

In the present study NRS 2002 score $\geq 4$ and ASA score $\geq 3$ were predictive for 90-day mortality after liver resection in multivariate analysis. The ASA score $\geq 3$ has been reported previously to increase the postoperative morbidity [29] and mortality $[2,30]$ after liver resection. However, the present study is the first to report the impact of nutritional risk screening on mortality after hepatectomy.

In univariate analysis the present study found five risk factors for 90-day mortality: ASA score 
Table III. Univariate analysis of risk factors for 90-day mortality in 203 elective liver resections for malignancy

\begin{tabular}{|c|c|c|c|}
\hline Parameter & Dead $(n=12)$ & Alive $(n=191)$ & $P$-value \\
\hline Age [years] & $77(55-80)$ & $67(27-89)$ & 0.186 \\
\hline Female gender & 4 & 51 & 0.738 \\
\hline \multicolumn{4}{|l|}{ Study period: } \\
\hline First 101 resections & 5 & 96 & 0.767 \\
\hline Second 102 resections & 7 & 95 & \\
\hline Charlson Comorbidity Index Score $>6$ & 8 & 73 & 0.068 \\
\hline ASA Score $\geq 3$ & 9 & 60 & 0.003 \\
\hline NRS $2002 \geq 4$ & 10 & 65 & 0.001 \\
\hline Albumin level $<35 \mathrm{~g} / \mathrm{dl}$ & 5 & 19 & 0.006 \\
\hline Preoperative chemotherapy & 3 & 64 & 0.754 \\
\hline Cirrhosis/fibrosis & 3 & 31 & 0.694 \\
\hline Colorectal liver metastases & 5 & 122 & 0.135 \\
\hline Hepatocellular carcinoma & 4 & 38 & 0.275 \\
\hline Cholangiocarcinoma & 2 & 20 & 0.623 \\
\hline Other malignancy & 1 & 11 & 1 \\
\hline Major hepatectomy & 7 & 54 & 0.046 \\
\hline Extrahepatic procedures & 6 & 60 & 0.209 \\
\hline Duration of surgery [min] & $272(180-360)$ & $230(110-630)$ & 0.087 \\
\hline Blood loss [ml] & $450(100-1200)$ & $400(50-2500)$ & 0.865 \\
\hline Transfusion & 8 & 68 & 0.037 \\
\hline
\end{tabular}

ASA - American Society of Anesthesiologists, NRS 2002 - Nutritional risk screening 2002. Continuous variables are reported as median and range. Dichotomous variables are reported as $N$. Continuous variables were compared using the Mann-Whitney test. Dichotomous variables were compared using Fisher's exact test. All variables with $p<0.2$ in univariate analysis were included in multivariate analysis.

$\geq 3$, major hepatectomy, perioperative transfusion, NRS score $\geq 4$ and albumin level $<35 \mathrm{~g} / \mathrm{l}$, confirming the findings of Dokmak et al. [2] for the first three variables and the results of Tzeng et al. [4] and Aloia et al. [16] for transfusion. However, in multivariate analysis only ASA score $\geq 3$ and NRS 2002 score $\geq 4$ remained significant. This may be due to the rather small study population.

The present study records a 90-day mortality of $5.9 \%(12 / 203)$ after elective surgery for malignancy, which is higher compared to $4.5 \%(66 / 1453)$ recently reported by Dokmak et al. [2]. However, the difference is not significant $(p=0.389)$ in a Pearson $\chi^{2}$ test. Other studies reported a similar 90-day mortality rate of $5.8 \%$ [31] to $10.1 \%$ [26] after liver resection. The 90-day mortality rate should be preferred over 30-day mortality, as suggested by Mayo et al., who concluded: "Reporting deaths that occur within a maximum of 30 days of surgery underestimates the mortality associated with hepatic resection. Traditional 30-day definitions of mortality are misleading and surgeons should report all perioperative outcomes that occur within 90 days of hepatic resection" [26].

The 90-day mortality registered in the present study was $4.4 \%$ for liver resection only versus $9.1 \%$ for liver resection with extrahepatic procedures ( $p=0.209)$. The difference was not significant because of the small number of patients (type II error). Indeed, one third of patients $(66 / 203)$ had simultaneous extrahepatic procedures, and colorectal resection $(n=40)$ was the most common. This is in accordance with others institutions: Jarnagin et al. [1] and Dokmak et al. [2] reported 37\% and 27.5\% rates of extrahepatic procedures, respectively.

Although the overall complication rate was rather high $(59.1 \%)$, most were of grade I or II in the Clavien-Dindo classification. The present study failed to register an increased rate of overall and infectious complication for patients with an NRS 2002 score $\geq 4$. However, septic shock (the most severe infectious complication) was significantly more frequently registered in patients with an NRS 2002 score $\geq 4$ and had a high mortality rate of $41.7 \%(5 / 12)$. 
Table IV. Multivariate analysis of risk factors for 90-day mortality in 203 elective liver resections for malignancy

\begin{tabular}{|c|c|c|c|c|}
\hline Covariates & Odds ratio & $95 \% \mathrm{Cl}$ & $P$-value & \\
\hline \multicolumn{5}{|c|}{ First step of multivariate analysis: inclusion of factors with $p<0.2$ in univariate analysis (Table III) } \\
\hline Age [years] & 0.99 & $0.92-1.06$ & 0.990 & Excluded \\
\hline Charlson Comorbidity Index Score > 6 & 4.38 & $0.85-22.46$ & 0.076 & \\
\hline ASA Score $\geq 3$ & 4.09 & $0.87-19.14$ & 0.073 & \\
\hline NRS $2002 \geq 4$ & 5.20 & $0.97-27.82$ & 0.053 & \\
\hline Albumin level $<35 \mathrm{~g} / \mathrm{dl}$ & 2.93 & $0.61-13.87$ & 0.175 & Excluded \\
\hline Colorectal liver metastases & 0.20 & $0.04-0.89$ & 0.035 & \\
\hline Major hepatectomy & 3.03 & $0.68-13.43$ & 0.145 & Excluded \\
\hline Duration of surgery [min] & 1.00 & $0.99-10.1$ & 0.567 & Excluded \\
\hline Transfusion & 1.77 & $0.40-7.80$ & 0.448 & Excluded \\
\hline \multicolumn{5}{|c|}{ Second step of multivariate analysis: inclusion of factors with $p<0.1$ in first step of multivariate analysis } \\
\hline Charlson Comorbidity Index Score > 6 & 2.76 & $0.68-11.16$ & 0.153 & Excluded \\
\hline ASA Score $\geq 3$ & 5.48 & $1.34-22.37$ & 0.018 & \\
\hline NRS $2002 \geq 4$ & 7.68 & $1.54-38.18$ & 0.013 & \\
\hline Colorectal liver metastases & 0.32 & $0.08-1.25$ & 0.103 & Excluded \\
\hline \multicolumn{5}{|l|}{ Final step of multivariate analysis } \\
\hline ASA Score $\geq 3$ & 6.20 & $1.56-24.53$ & 0.009 & \\
\hline NRS $2002 \geq 4$ & 9.24 & $1.92-44.39$ & 0.005 & \\
\hline
\end{tabular}

$\mathrm{Cl}$ - confidence interval for the odds ratio.

Nutritional risk factors for hepatobiliary surgery were reported by Halliday et al. [15] in a study of 32 patients in 1988. In their study weight loss $>15 \%$ and albumin level $<30 \mathrm{~g} / \mathrm{dl}$ were associated with postoperative mortality and morbidity. However, the majority of patients had biliary and

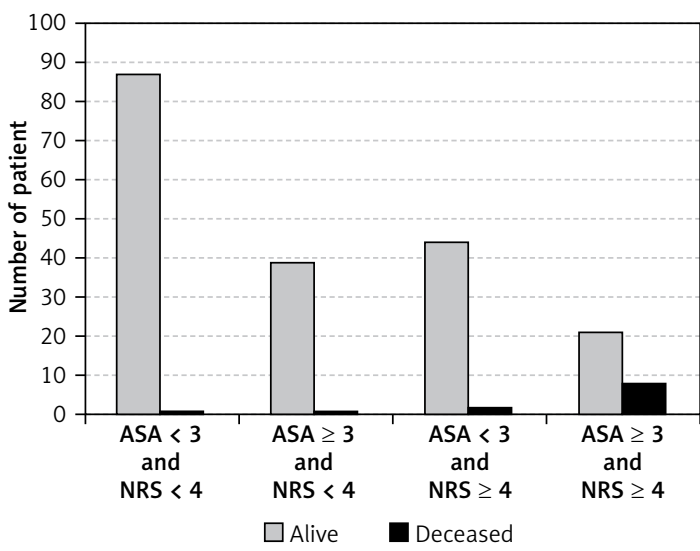

Figure 1. Distribution of patients undergoing 203 liver resections for malignancy according to risk factors for 90-day mortality: NRS 2002 score $\geq 4$ and ASA score $\geq 3$. The number of patients (alive and deceased at 90 days postoperatively) is given for each group. The 90-day mortality was $1.1 \%$ (1/88), $2.5 \%$ (1/40), $4.3 \%(2 / 46)$ and $27.6 \%$ (8/29), respectively bypass procedures and only 6 patients underwent hepatectomy, limiting the conclusion of Halliday et al. for liver resection.

Nutritional risk screening 2002 was prospectively studied by Schwegler et al. [14] in surgery for colorectal cancer. A significantly higher rate of postoperative complications (62\% vs. $39.8 \%, p=$ 0.004 ) was registered for patients at nutritional risk (NRS $\geq 3$ points). Unlike the present study, complications were not classified according to Clavien-Dindo. Postoperative mortality was not significantly higher in patients with nutritional risk: $7 \%$ vs. $1.8 \%(p=0.085)$. However, in their study only in-hospital mortality and complications were registered. The authors concluded "that more morbidity and possibly mortality would have been recorded if the time frame had been longer". Recently NRS 2002 was used by Jie et al. [20] in a study of nutritional support in 1085 abdominal surgical patients. In their study a postoperative complication rate of $41.6 \%$ (50/120) was reported for patients with an NRS 2002 score $\geq 5$, vs. $23.2 \%$ (91/392) in patients with an NRS 2002 score of 3 or $4(p<0.001)$. Postoperative 31 -day mortality was $1.6 \%(2 / 120)$ in patients with an NRS 2002 score $\geq 5$ vs. $0.5 \%(2 / 392)$ in patients with an NRS 2002 score of 3 or $4(p=0.235)$. Although the 
Table V. Postoperative complications and mortality within 90 days after 203 elective liver resections for malignancy according to the preoperative value of the Nutritional Risk Screening 2002 Score (NRS)

\begin{tabular}{|c|c|c|c|}
\hline Parameter & $\begin{array}{c}\text { NRS score } 2 \text { or } 3 \\
\quad(n=128)\end{array}$ & $\begin{array}{c}\text { NRS score } \geq 4 \\
(n=75)\end{array}$ & $P$-value \\
\hline Number of patients with complications $(n=120)$ & $73(57.0 \%)$ & $47(62.6 \%)$ & 0.462 \\
\hline Number of patients with infectious complications & $42(32.8 \%)$ & $30(40.0 \%)$ & 0.362 \\
\hline Number of patients with septic shock & $3(2.3 \%)$ & $9(12 \%)$ & 0.007 \\
\hline \multicolumn{4}{|c|}{ Number of complications $(n=212)$ according to the Clavien-Dindo classification: } \\
\hline Grade I $(n=42)$ & $23(17.9 \%)$ & $19(25.3 \%)$ & 0.281 \\
\hline Grade II $(n=104)$ & $64(50.0 \%)$ & $40(53.3 \%)$ & 0.665 \\
\hline Grade III $(n=33)$ & $21(16.4 \%)$ & $12(16.0 \%)$ & 1 \\
\hline Grade IV $(n=21)$ & $10(7.8 \%)$ & $11(14.7 \%)$ & 0.152 \\
\hline Grade V, 90-day mortality $(n=12)$ & $2(1.5 \%)$ & $10(13.3)$ & 0.001 \\
\hline \multicolumn{4}{|l|}{ Subgroup analysis of 90-day mortality: } \\
\hline Liver resection only $(n=137)$ & $2 / 97(2.1 \%)$ & $4 / 40(10.0 \%)$ & 0.060 \\
\hline Extrahepatic procedures $(n=66)$ & $0 / 31(0 \%)$ & $6 / 35(17.1 \%)$ & 0.025 \\
\hline Age $<70$ years $(n=115)$ & $2 / 81(2.5 \%)$ & $3 / 34(8.8 \%)$ & 0.152 \\
\hline Age $\geq 70$ years $(n=88)$ & $0 / 47(0 \%)$ & $7 / 41(17.1 \%)$ & 0.003 \\
\hline Minor hepatectomy $(n=142)$ & $1 / 94(1.1 \%)$ & $4 / 48(8.3 \%)$ & 0.044 \\
\hline Major hepatectomy $(n=61)$ & $1 / 34(2.9 \%)$ & $6 / 27(22.2 \%)$ & 0.037 \\
\hline
\end{tabular}

Dichotomous variables are reported as $N$ and were compared using Fisher's exact test. All complications were registered and classified according to the Clavien-Dindo classification [28].

authors included 279 patients with hepatobiliary surgery in their study, no data regarding this specific population was presented.

In a multi-institutional study by Tzeng et al. [4], 30-day mortality was registered in 43 of 214 patients $\geq 75$ years who had major complications after a liver resection. In their study, the 30-day mortality increased with the number of major complications. However, the impact of nutritional risk on complication and mortality was not studied. To improve surgical outcome Tzeng et al. proposed to "limit the extent and complexity of resection procedures for high risk patients".

The high prevalence of nutritional risk (NRS $2002 \geq 3$ ) observed in the present study and the consequences of nutritional risk for the outcome after surgery explain the clinical interest for nutritional support. However, no consensus on the optimal nutritional support in liver resection has been reached [32, 33]. A Cochrane review by Koretz et al. found no impact on postoperative mortality and morbidity for parenteral, enteral or oral nutritional support in surgery for liver disease [33]. In the authors' institution during the study period preoperative nutritional support was mainly provided with oral immunonutrition [23, 34, 35], whereas postoperative nutritional support was mainly provided with parenteral nutrition [36]. The impact of nutri- tional support on outcome was not analyzed in the present study, as significant covariate imbalances were registered for patients with nutritional support versus those without nutritional support. The authors have reported a propensity score matched case-control analysis of preoperative immunonutrition versus no nutritional support in liver resection, and no benefit of preoperative immunonutrition with regard to postoperative complications could be demonstrated [35]. The impact of nutritional support on outcome should be analyzed in a randomized trial [33, 34, 36].

The major limitation of the present study was its retrospective design. The impact of nutritional risk screening on postoperative mortality and complications after liver resection should be studied in a prospective trial. Furthermore, the number of patients in the present study was rather limited. Therefore, the statistical value of the present analysis should be regarded with caution. In the present study one third of patients had simultaneous extrahepatic procedures which were a confounding factor for complications and mortality. Patients with emergency liver resection and with benign disease were excluded from the present study. However, nutritional risk may also be present in these settings and further studies should be performed. 


\section{Clinical implications}

What were the consequences of the present study for the surgical practice in the authors' institution? NRS 2002 score $\geq 4$ and ASA score $\geq 3$ were predictive for increased 90-day mortality after elective liver resection for malignancy. Postoperative mortality was in most cases a consequence of infectious complications. The ASA score cannot be changed, and the impact of perioperative nutritional support to influence postoperative outcome after liver resection remains questionable [32-35]. A careful selection of surgical procedures in patients with nutritional risk and an ASA score $\geq 3$ is required to reduce perioperative complications. In the authors' institution, in the light of the present data and following the conclusions of Tzeng et al. [4], the "extent and complexity" of liver resection and simultaneous extrahepatic procedures will be limited in patients with an NRS 2002 score $\geq 4$ and an ASA score $\geq 3$.

In conclusion, in the present study NRS 2002 score $\geq 4$ and ASA score $\geq 3$ were predictive for 90-day mortality after elective liver resection for malignancy. Further studies are necessary to evaluate the clinical value of nutritional risk screening for liver resection.

\section{Conflict of interest}

The authors declare no conflict of interest.

\section{References}

1. Jarnagin WR, Gonen M, Fong $Y$, et al. Improvement in perioperative outcome after hepatic resection: analysis of 1803 consecutive cases over the past decade. Ann Surg 2002; 236: 397-407.

2. Dokmak S, Ftériche FS, Borscheid R, Cauchy F, Farges O, Belghiti J. 2012 liver resection in the 21st century: we are far from zero mortality. HPB 2013; 15: 908-15.

3. Adam R, Frilling A, Elias D, et al. Liver resection of colorectal metastases in elderly patients. Br J Surg 2010; 97: 366-76.

4. Tzeng CW, Cooper AB, Vauthey JN, Curley SA, Aloia TA. Predictors of of morbidity and mortality after hepatectomy in elderly patients: analysis of 7621 NSQIP patients. HPB 2014; 16: 459-68.

5. Zacharias T, Jaeck D, Oussoultzoglou E, Bachellier $P$, Weber JC. First and repeat resection of colorectal liver metastases in elderly patients. Ann Surg 2004; 240: 858-65.

6. Rubbia-Brand L, Audard V, Sartoretti P, et al. Severe hepatic sinusoidal obstruction associated with oxaliplatin-based chemotherapy in patients with metastatic colorectal cancer. Ann Oncol 2004; 15: 460-6.

7. Vauthey JN, Pawlik TM, Ribero D, et al. Chemotherapy regimen predicts steatohepatitis and an increase in 90day mortality after surgery for hepatic colorectal metastases. J Clin Oncol 2006; 24: 2065-72.

8. Mathur AK, Ghaferi AA, Osborne NH, et al. Body mass index and adverse perioperative outcomes following hepatic resections. J Gastrointest Surg 2010; 14: 1285-91.
9. Izzo F, Piccirillo M, Albino V, et al. Prospective screening increases the detection of potentially curable hepatocellular carcinoma: results in 8900 high-risk patients. HPB 2013; 15: 985-90.

10. Paillaud E, Liuu E, Laurent M, et al. Geriatric syndromes increased the nutritional risk in elderly cancer patients independently from tumour site and metastatic status. The ELCAPA-05 cohort study. Clin Nutr 2014; 33: 330-5.

11. Paillaud E, Caillet P, Campillo B, Bories PN. Increased risk of alteration of nutritional status in hospitalized elderly patients with advanced cancer. J Nutr Health Aging 2006; 10: 91-5.

12. Schiesser $M$, Kirchhoff $P$, Müller MK, Schäfer M, Clavien PA. The correlation of nutrition risk index, nutrition risk score, and bioimpedance analysis with postoperative complications in patients undergoing gastrointestinal surgery. Surgery 2009; 145: 519-26.

13. Perioperative total parenteral nutrition in surgical patients. The Veterans Affairs Total Parenteral Nutrition Cooperative Study Group. N Engl J Med 1991; 325: 525-32.

14. Schwegler I, von Holzen A, Gutzwiller JP, Schlumpf R, Mühlebach S, Stanga Z. Nutritional risk is a clinical predictor of postoperative mortality and morbidity in surgery for colorectal cancer. Br J Surg 2010; 97: 92-7.

15. Halliday AW, Benjamin IS, Blumgart LH. Nutritional risk factors in major hepatobiliary surgery. J Parenter Enteral Nutr 1988; 12: 43-8.

16. Aloia TA, Fahy BN, Fischer CP, et al. Predicting poor outcome following hepatectomy: analysis of 2313 hepatectomies in the NSQIP database. HPB 2009; 11: 510-5.

17. Huang L, Li J, Yan JJ, Liu CF, Wu MC, Yan YQ. Prealbumine is predictive for postoperative liver insufficiency in patients undergoing liver resection. World J Gastroenterol 2012; 18: 7021-5.

18. Weimann A, Braga M, Harsanyi L, et al. ESPEN guidelines on enteral nutrition: surgery including organ transplantation. Clin Nutr 2006; 25: 224-44.

19. Kondrup J, Rasmussen HH, Hamberg O, Stanga Z; ESPEN working group. Nutritional risk screening (NRS 2002): a new method based on an analysis of controlled clinical trials. Clin Nutr 2003; 22: 321-36.

20. Jie B, Jiang ZM, Nolan MT, Zhu SN, Yu K, Kondrup J. Impact of preoperative nutritional support on clinical outcome in abdominal surgical patients at nutritional risk. Nutrition 2012; 28: 1022-7.

21. Claudot F, Alla F, Fresson J, Calvez T, Coudane H, Bonaïti-Pellié $C$. Ethics and observational studies in medical research: various rules in a common framework. Int J Epidemiol 2009; 38: 1104-8.

22. Treska V, Skalicky T, Sutnar A, et al. Prognostic importance of some clinical and therapeutic factors for the effect of portal vein embolization in patients with primarily inoperable colorectal liver metastases. Arch Med Sci 2013; 9: 47-54.

23. Mariette C, Alves A, Benoist S, Bretagnol F, Mabrut JY, Slim K. Perioperative care in digestive surgery. Guidelines for the French Society of Digestive Surgery. Ann Chir 2005; 130: 108-24.

24. Société française d'anesthesie et de reanimation. Antibioprophylaxis in surgery and interventional medicine (adult patients). Actualization 2010. Ann Fr Anesth Reanim 2011; 30: 168-90.

25. Strasberg SM. Nomenclature of hepatic anatomy and resections: a review of the Brisbane 2000 system. J Hepatobiliary Pancreat Surg 2005; 12: 351-5.

26. Mayo SC, Shore AD, Nathan H, et al. Refining the definition of perioperative mortality following hepatectomy 
using death within 90 days as the standard criterion. HPB 2011; 13: 473-82.

27. Bone RC, Balk RA, Cerra FB, et al. Definitions for sepsis and organ failure and guidelines for the use of innovative therapies in sepsis. Chest 1992; 101: 1644-55.

28. Dindo D, Demartines N, Clavien PA. Classification of surgical complications: a new proposal with evaluation in a cohort of 6336 patients and results of a survey. Ann Surg 2004; 240: 205-13.

29. Belghiti J, Hiramatsu K, Benoist S, Massault P, Sauvanet A, Farges O. Seven hundred forty-seven hepatectomies in the 1990s: an update to evaluate the actuel risk of liver resection. J Am Coll Surg 2000; 191: 38-46.

30. Schroeder RA, Marroquin CE, Bute BP, Khuri S, Henderson WG, Kuo PC. Predictive indices of morbidity and mortality after liver resection. Ann Surg 2006; 243: 373-9.

31. Farges O, Goutte N, Bendersky N, et al. Incidence and risks of liver resection: an all-inclusive French nationwide study. Ann Surg 2012; 256: 697-704.

32. Richter B, Schmandra TC, Golling M, Bechstein WO. Nutritional support after open liver resection: a systematic review. Dig Surg 2006; 23: 139-45.

33. Koretz RL, Avenell A, Lipman TO. Nutritional support for liver disease. Cochrane Database Syst Rev 2012; 5 : CD008344.

34. Mikagi K, Kawahara R, Kinoshita H, Aoyagi S. Effect of preoperative immunonutrition in patients undergoing hepatectomy; a randomized controlled trial. Kurume Med J 2011; 58: 1-8.

35. Zacharias T, Ferreira N, Carin AJ. Preoperative immunonutrition in liver resection - a propensity score matched case-control analysis. Eur J Clin Nutr 2014; 68: 964-9.

36. Fan ST, Lo CM, Lai EC, Chu KM, Liu CL, Wong J. Perioperative nutritional support in patients undergoing hepatectomy for hepatocellular carcinoma. N Eng J Med 1994; 331: 1547-52. 